\title{
ISOENZYME MARKERS FOR ASSESSMENT OF IN VITRO PLANTS FROM RUSCUS ACULEATUS L.
}

\author{
T. Ivanova*, G. Angelov, Y. Bosseva, Ch. Gussev, D. Dimitrova, T. Stoeva \\ Department of Plant and Fungal Diversity and Resources, Institute of Biodiversity and Ecosystem \\ Research, Bulgarian Academy of Sciences, Sofia, Bulgaria
}

\begin{abstract}
PURPOSE: Ruscus aculeatus L. is an economically important ornamental and medicinal plant gathered mainly from the wild. Micropropagation protocols have been suggested for rapid production of clonal material and ex situ conservation of Ruscus species to avoid further over-exploitation of its natural resources. Variances in propagation rate and plant habitus were reported previously as important traits of the specific clones. Izoenzyme markers are proposed for assessment of the possible somaclonal variability induced during the in vitro propagation and the efficiency of the micropropagation procedure. METHODS: The isoenzyme profiles of three enzyme systems (peroxidases, esterases and acid phosphatase) of seven in vitro clones and native control were compared using discontinuous PAGE system. RESULTS: Induction of additional isoforms was frequent in the in vitro plants and clonespecific variations were detected. Acid phosphatase profiles were most polymorphic compared to less variable esterase and peroxidase ones. Isoenzyme profiles were not particularly correlated with the geographical origin of the accessions. CONCLUSIONS: The less polymorphic peroxidase and esterase systems could be used as markers for somaclonal changes by in vitro cultivation of $R$. aculeatus and selection of prospective clones.
\end{abstract}

Key words: PAGE electrophoresis, micropropagation, butcher's broom

\section{INTRODUCTION}

Ruscus aculeatus L. is naturally occurring in the Mediterranean area (incl. North Africa), East Europe, Central Hungary, Caucasus and Crimea (1). The species is widely known medicinal and ornamental plant gathered mainly from the wild. Hence its natural resources are diminishing. The species is included in 'Habitats' Directive 92/43/EEC (Annex $\mathrm{Vb}$ ) and the European Plant Red List. In Bulgaria the collection of $R$. aculeatus from its natural accessions is regulated by the national Biodiversity Act (2007) and the Medicinal Plants Act (2000). In vitro cultivation of $R$. aculeatus has been investigated previously and shows some irregularities in the propagation due to recalcitrance, slow development and unclear effect of growth regulators (2). Clonal origin was pointed as an important factor for the distinctiveness in the development pattern,

\footnotetext{
*Correspondence to: Teodora Ivanova, Institute of Biodiversity and Ecosystem Research, BAS, 23, Acad. G. Bonchev Str., 1113, Sofia, Bulgaria, email: tai@bio.bas.bg
}

propagation rate and ruscogenin biosynthetic capacity of the in vitro clones (3).

Analysis of the isoenzyme profiles of seven $R$. aculeatus in vitro clones is presented in order to assess the variability in directly regenerated shoots and to test the possibility for the isoenzymes to be used as markers in assessment of the micropropagation effectiveness.

\section{MATERIAL AND METHODS}

Plant material and culture conditions

Seeds were collected from wild populations in Northwest (S) and Southeast (V, MD) Bulgaria as part of the Millennium Seed Bank Partnership collection missions. Voucher specimens were deposited in the Herbarium of Institute of Biodiversity and Ecosystem Research (SOM). Shoot cultures were initiated from rhizome segments of seedlings by previously described technique (4). Cultures were maintained continuously on MS media with $1 \mathrm{mg} / \mathrm{L}$ 6-benzylaminopurine, $0.5 \mathrm{mg} / \mathrm{L} \alpha$ naphtaleneacetic acid, $0.8 \mathrm{mg} / \mathrm{L}$ Plantagar (all supplied by Duchefa, Netherlands) and $30 \mathrm{~g}$ $\mathrm{mg} / \mathrm{L}$ commercial sugar. All media were 
IVANOVA T., et al.

adjusted to $\mathrm{pH} 5.75$ prior to sterilization and autoclaved at $121{ }^{\circ} \mathrm{C} / 1 \mathrm{~atm}$ for 20 minutes. The cultures were maintained in VitroVent ${ }^{\circledR}$ containers (with $125 \mathrm{~mL}$ medium, at $16 / 8 \mathrm{~h}$ photoperiod and $23 \pm 1{ }^{\circ} \mathrm{C}$. Cultures were transferred onto fresh media every 8 weeks and every shoot with minimal height of $0.5 \mathrm{~mm}$ was detached and grown separately on the same medium. Propagation rate, shoot growth and appearance were recorded for at least 18 months. Data were processed statistically by Duncan's multiple range test (SPSS Inc.).

Samples for the isoenzyme analysis were collected from fully-developed shoot clusters.
Protein extraction and isoenzyme profiles of anodal isoforms of esterase (EST), peroxidase (POD) and acid phosphatase (ACP) using discontinuous PAGE system were done according to Angelov (2003) (6).

\section{RESULTS}

Propagation rates of the clones differed significantly being about twice as high in clones S52 and MD1 compared to others from same geographical origin (Figure 1). Shoot morphology in all clones was normal and abnormalities were uncommon. However some differences in phylloclade size and form were observed (Figure 2).

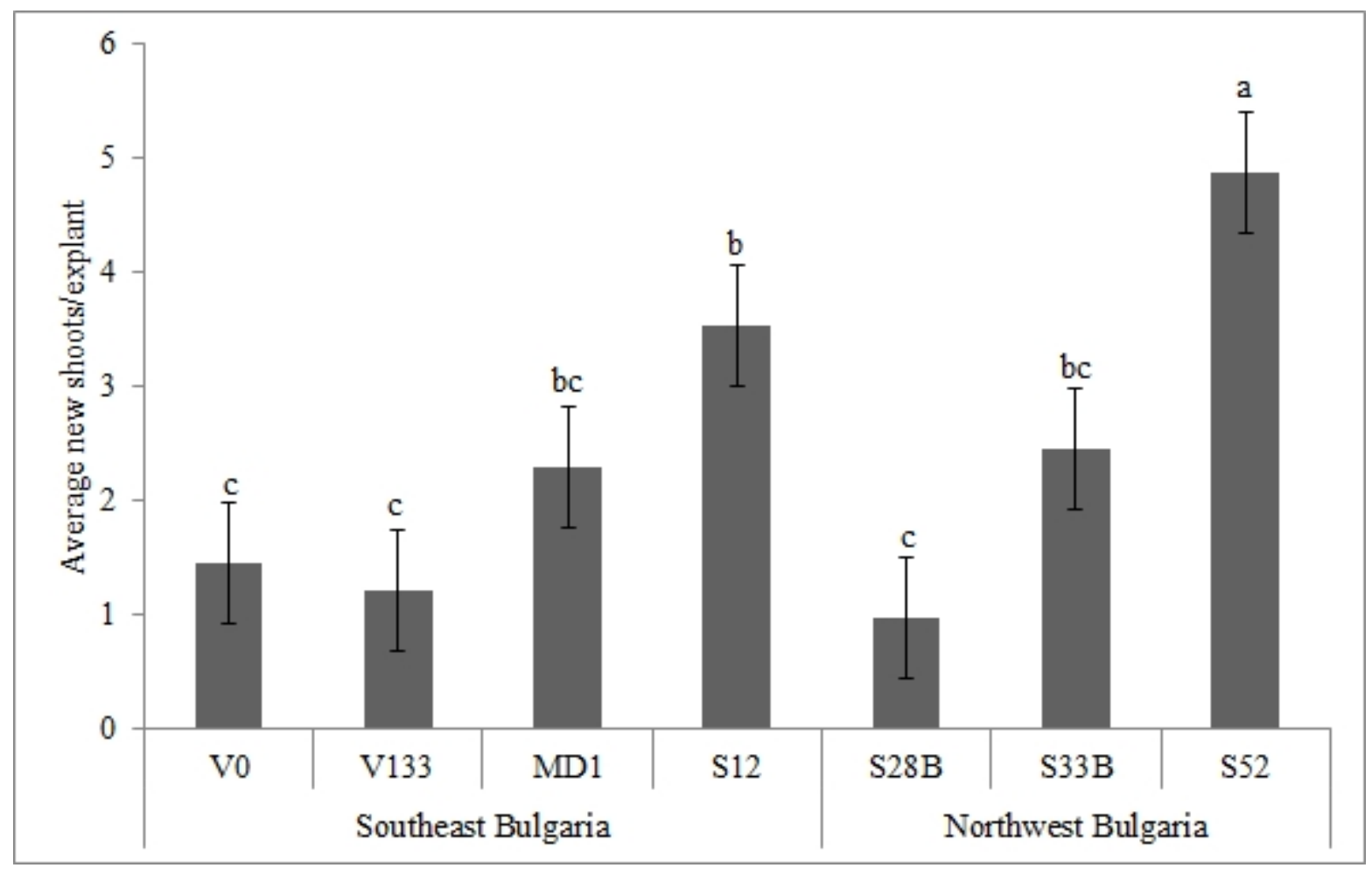

Figure 1. Propagation rate of Ruscus aculeatus in vitro clones.

Values $( \pm \mathrm{SD})$ followed by same letters are not significantly different at $\mathrm{p}=0.05$ (Duncan's multiple range test).

All in vitro clones had one common POD isoform with the native control and additional one or two slower ones (Figure 3). Most clones had one or two POD isoforms. Three or four isoforms were detected in two of the clones from the Southeast Bulgaria - V0 and V133 and one from the Northwest - S52.

Most of the in vitro clones exhibited at least one of the EST isoforms typical for the native control (Figure 4). Only clone S28B has exactly same profile as the control. Clone
V133 expressed none of the native isoforms. Induction of new slower isoform 12 was detected by clones S33B and V0.

ACP profiles appeared most polymorphic with induction of many new isoforms in the in vitro plants (Figure 5). Most of the induced isoforms were slow; some were unique for the specific clone. Largest number of newly induced isoforms was found in clone S33B. The slowest isoforms 10 and 12 were unique for the same clone. 


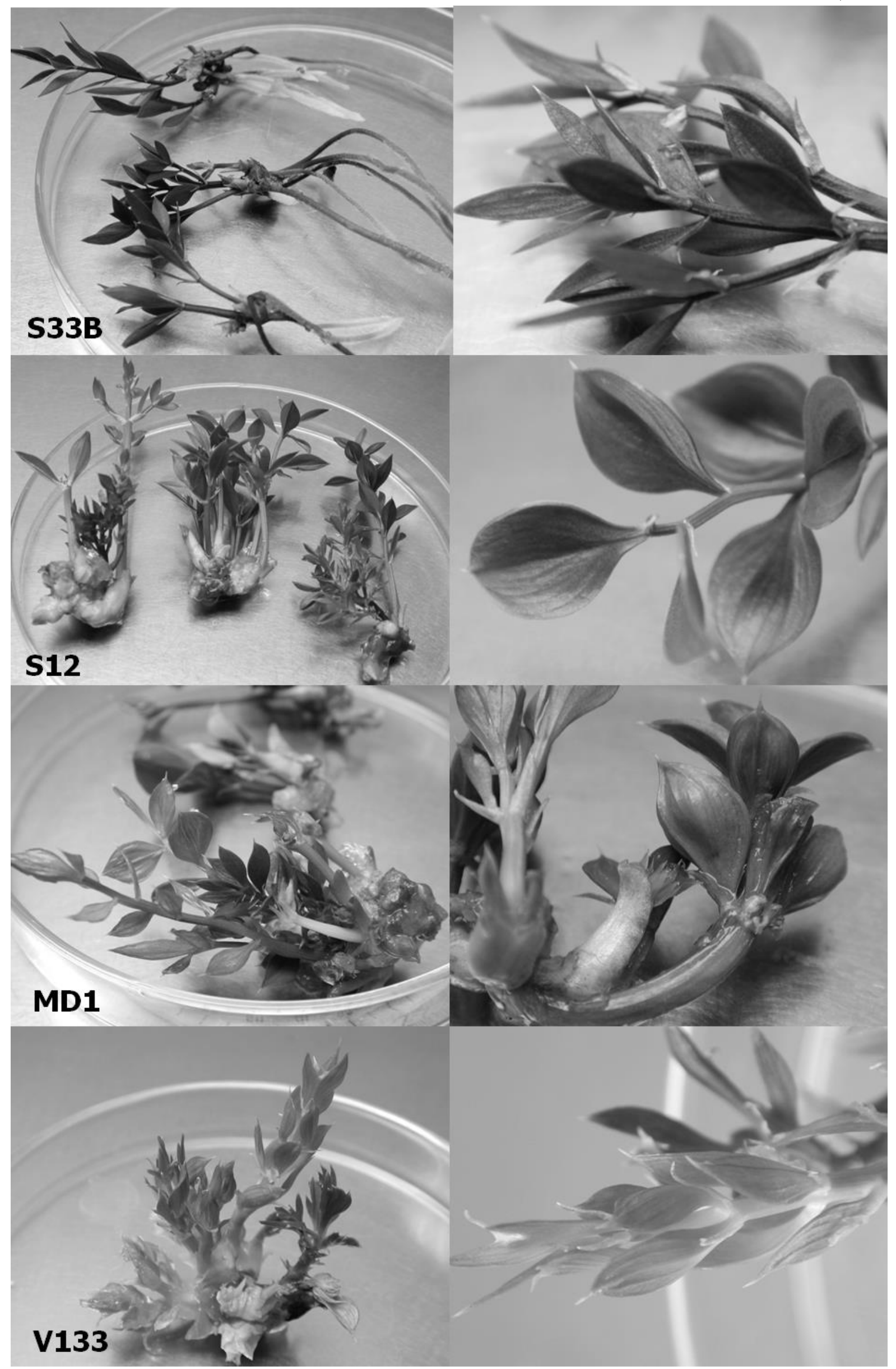

Figure 2. Shoot morphology of $R$. aculeatus in vitro clones

Clones S33B and S12 - Northwest Bulgarian origin; clones MD1 and V133 - Southeast Bulgarian origin 


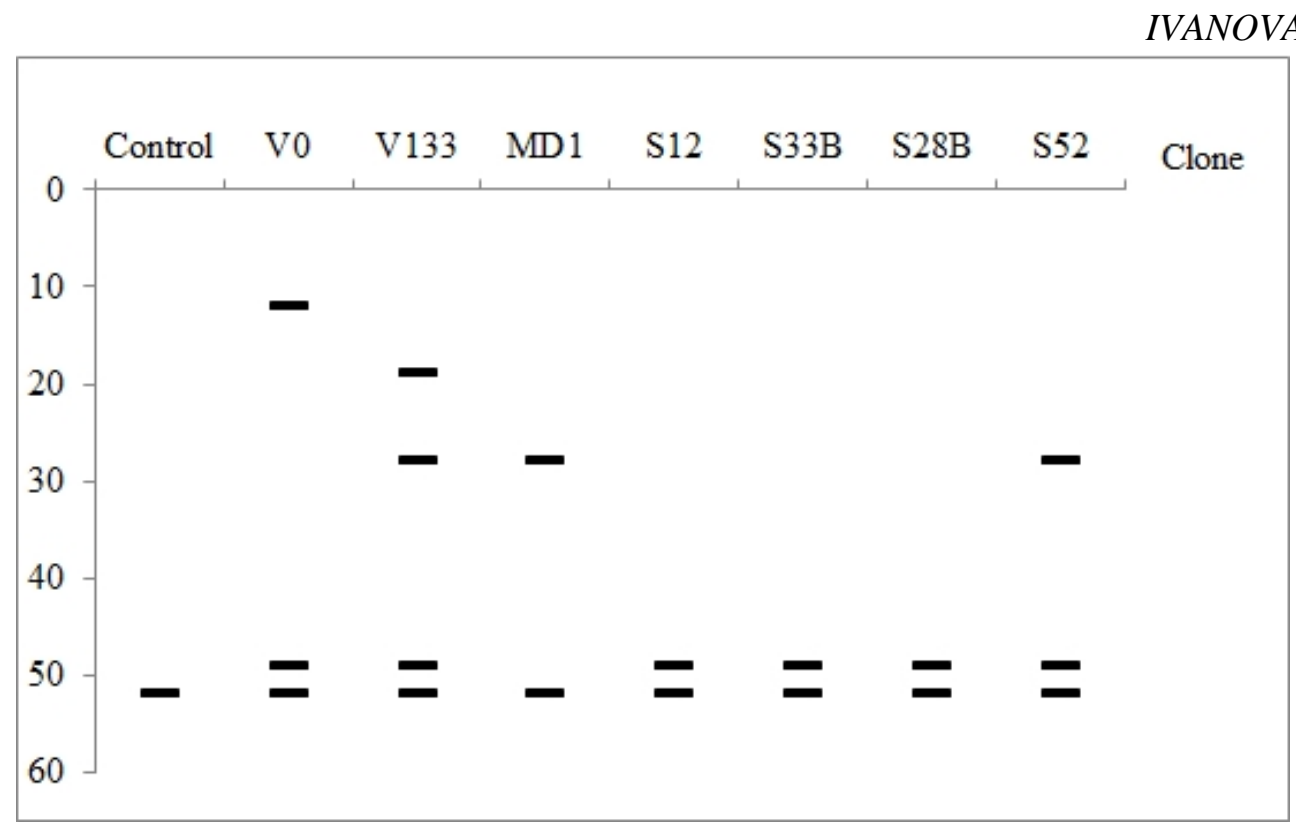

Figure 3. Schematic peroxidase isoenzyme profiles of $R$. aculeatus plants.

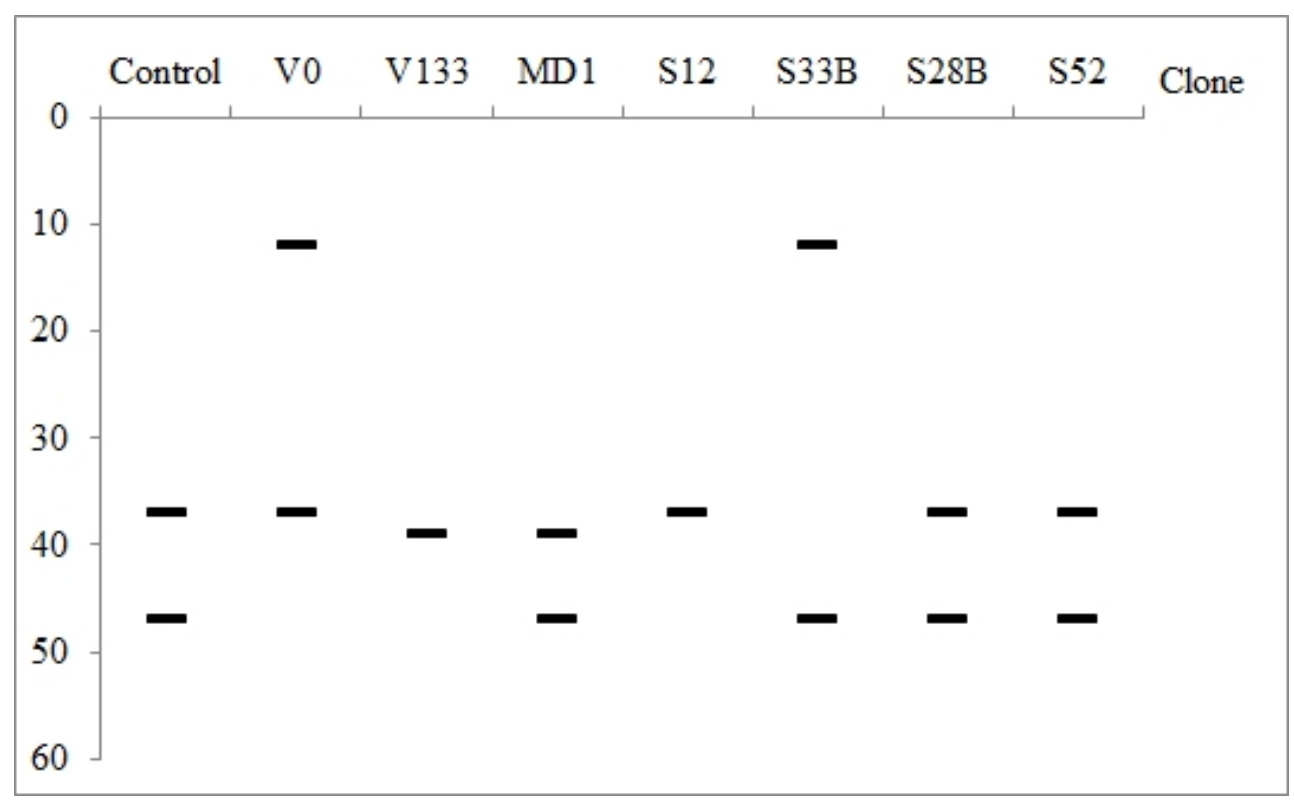

Figure 4. Schematic esterase isoenzyme profiles of $R$. aculeatus plants.

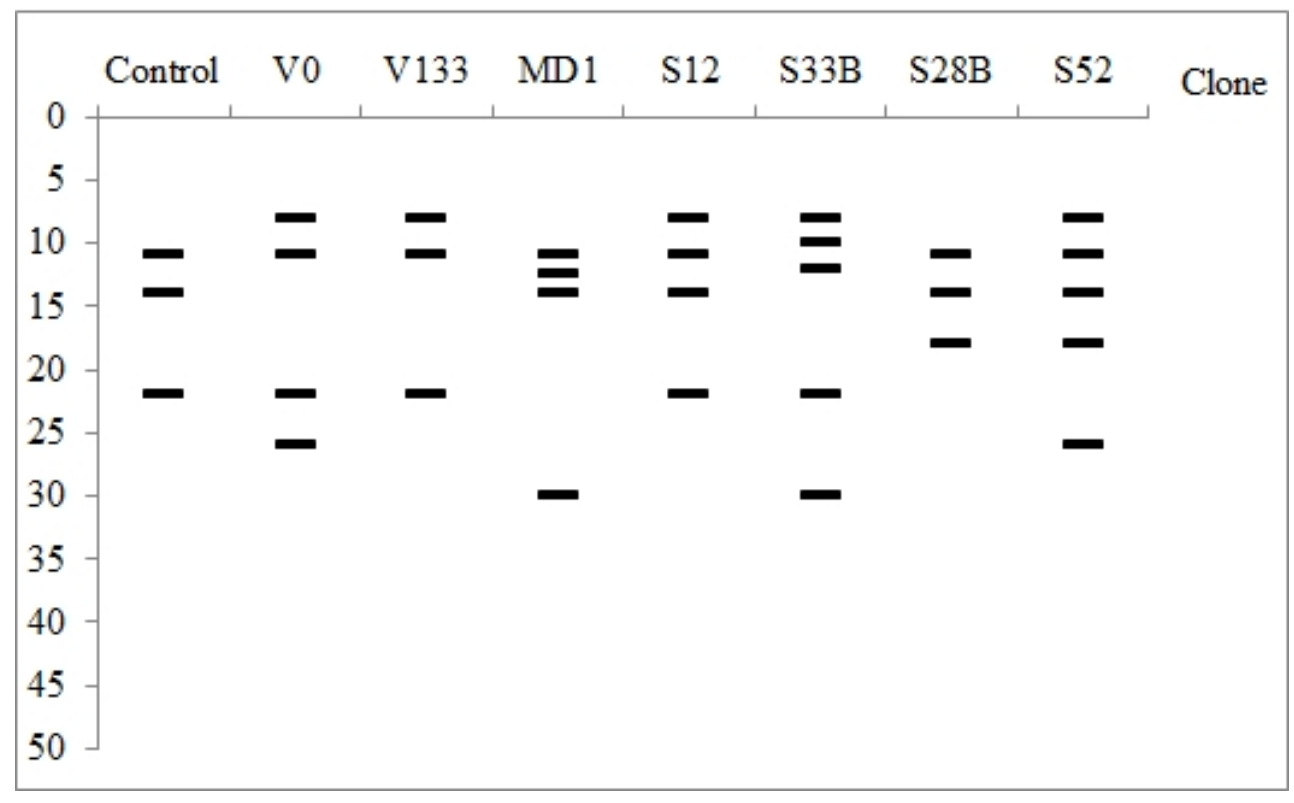

Figure 5. Shematic acid phosphatase isoenzyme profiles of $R$. aculeatus plants. 


\section{DISCUSSION}

The distinctive difference in propagation rate and phylloclade morphology of the studied $R$. aculeatus plants imply that the observed variation in the isoenzyme profiles could not be attributed only to the cultivation conditions. Previously reported in vitro cultivation of $R$. aculeatus form Romania did not showed effect on POD patterns (7). However their data showed at least 3 or 4 isoforms both in native and in vitro plants. Common POD isoform 52 was typical for $R$. hypoglossum as well (8). Our results suggest that isoenzyme profiles of the $R$. aculeatus plants are clone-specific and could not be particularly correlated with the geographical origin of the accessions. Previously reported highly ruscogenin yielding clones S12 and V133 (3) exhibited same or less polymorphic EST patterns. On the other hand POD pattern of the V133 was most polymorphic. The dissociation of the POD and EST isoforms and induction of new forms was related to somaclonal variation in in vitro plants in other species as well (9-11). All isoform of the acid phosphatase were very intensive unlike previous report previously (7) and highly polymorphic regardless of the clone origin. In conclusion, obtained results demonstrate that less polymorphic POD and EST systems could be used as markers for somaclonal changes by in vitro cultivation of $R$. aculeatus and selection of prospective clones.

\section{ACKNOWLEDGMENTS}

Authors are thankful to RBG Kew Millenium Seed Bank staff and the coordinator for Bulgaria (C. Trivedi) for the cooperation.

\section{REFERENCES}

1. Yeo, P., Ruscus L. In: Tutin et al., (eds.) Flora Europaea Vol. 5. Alismataceae to Orchidaceae (Monocotyledones), Cambridge University Press, UK, pp 71, 1980.

2. Moyano, E., Montero M., Bonfill M., Cusidó R., Palazón J., Piñol M., In vitro micropropagation of Ruscus aculeatus. Biol Plant, 50: 441-443, 2006.

3. Ivanova, T., Dimitrova, D., Gussev, Ch., Bosseva, Y., Stoeva, T., Ex situ conservation of Ruscus aculeatus L. ruscogenin biosynthesis, genome size stability and propagation traits of tissuecultured clones. Biotechnology \& Biotechnological Equipment, 29 (1): 27-32, 2015.

4. Ivanova, T., Gussev, Ch., Bosseva, Y., Stanilova, M., Stoeva, T., In vitro regeneration of Ruscus aculeatus L. effective micropropagation by shoot cultures. Prop Ornam Plants, 8 (1): 39-41, 2008

5. Murashige, T., Skoog, F., A revised medium for rapid growth and bioassays with tobacco tissue cultures. Physiol Plant, 15:473-497, 1962.

6. Angelov, G., Isoenzyme variation and genetic relationships among Eliytrigia junceiformis, E. $\times$ litorea and E. repens (Triticeae: Poaceae). Ann Bot Fenn, 40: 8370, 2003.

7. Banciu, C., Mitoi, M., Brezeanu, A., Biochemical peculiarity of in vitro morphogenesis under conservation strategy of Ruscus aculeatus L. Ann For Res, 52: 109-116, 2009.

8. Ivanova, T., Dimitrova, D., Angelov, G., Gussev, Ch., Bosseva, Y., Stoeva, T., Callus cultures and indirect regeneration of Ruscus hypoglossum in vitro. Bulg J Agric Sci, 19(2): 49-51, 2013.

9. Eastman, P., Webster, F., Pitel, J., Roberts, D., Evaluation of somaclonal variation during somatic embryogenesis of interior spruce (Picea engelmannii complex) using culture morphology and isozyme analysis. Plant Cell Report, 10:425-430, 1991.

10.Carini, F., De Pasquale, F. Micropropagation of Citrus. In: Mohan S. and Ishii K. (eds.), Micropropagation of Wood Tree and Fruits, Kluwer Academic Publishers, London, pp 589-619, 2003.

11.Carvalho, M. T. V., Derbyshire, E., Martins-Corder, M. P., Mendes, B. M.J., Neto A., Isozyme and dissociated protein profiles of normal plants and somaclonal variants of Banana obtained by in vitro culture. Acta Hort (ISHS), 490:437-444, 1998. 